\title{
Leslie Matrix Application in Determining Number and Growth Rate of Female Population
}

\author{
Dewi Anggreini*, Ratri Candra Hastari \\ Mathematics Education Department, STKIP PGRI Tulungagung, \\ J1. Mayor Sujadi Timur No.7 Tulungagung 66221. Tel. +62-355-321426, Fax. +62-355-321426, East Java, Indonesia \\ *Email: anggreini_004@yahoo.com
}

\begin{abstract}
Anggreini D, Hastari RC. 2017. Leslie Matrix Application in Determining Number and Growth Rate of Female Population. Proc Internat Conf Sci Engin 1: 165-170. Population projections are needed to meet current data requirements and estimate future population numbers. The compilation of population growth models besides being based on continuous solutions needs to be evaluated more deeply with discrete solutions. Leslie's matrix model is a discrete model that projects the age group. Mathematical approach is very important used in Leslie matrix model that is follow matrix method. This study aimed to determine the number of female population in the Karesidenan Kediri Existence based on birth rate and life expectancy using Leslie Matrix and determine the growth rate of female population by using Leslie matrix eigenvalues value. The research method first determine the subject of research, second collect research data, data analysis and last draw conclusions. The data of this study were obtained from BPS of East Java Province, namely the number of female population from 2010-2015. The results of this study indicate that Leslie's matrix model is a discrete model because the data on the number of female population in the Eks-Karesidenan Kediri divided into fourteen age intervals constructed using fertility and life expectancy. From the result analysis using Maple program, the number of female population in Eks Karesidenan Kediri tends to increase with positive eigenvalue greater than one or in other words the rate of population growth tends to be positive. The success of Leslie's matrix model is in its application to predict the number of female populations in Karesidenan Kediri in 2021
\end{abstract}

Keywords: Eigenvalues, Eigenvectors, Leslie's matrix, Population

\section{INTRODUCTION}

Eks-Karesidenan kediri is part of the province of East Java in the eastern part of Java island. The Karesidenan Kediri area includes Kediri, Blitar, Tulungagung, Trenggalek, Blitar and Nganjuk. It is known that almost all development plans need to be supported by population data, distribution and arrangement according to the age group of the population relevant to the plan. The data required not only concern the circumstances at which the plan was drawn up, but also the information of the past and more importantly the forecast information in the future. Past population data can be obtained from the results of surveys and census, while to meet the needs of current and future population data needs to be made population projection, the estimated population and composition in the future. (Central Bureau of Statistics, 2013).

Science has grown tremendously in recent years, including mathematical modeling. According Iswanto (2012), the development of mathematical models can be represented on the problems that occur in everyday life. Thus there is a strong relationship between applied science and mathematics represented by mathematical models designed and applied with the help of computer science, to facilitate simulation of real-world systems. Population growth is one example of Linear Algebra application in Biology and especially quantitative Ecology. In Ecology, population growth is often referred as "population dynamics". Ecology is usually defined as the relationship between living things and their environment (Tarumingkeng, 1994).
In general, the growth form of a living being is a continuous or continuous process. However, population studies should also be approached from discrete time reviews. The use of discrete patterns is also based on the observation of the population which is generally done intervals of certain periods such as a day, a week, and a number of units according to the design of the researcher concerned. Based on these considerations, the compilation of growth models other than based on continuous solutions needs to be evaluated more deeply with discrete solutions (Tarumingkeng, 1994).

There are several studies on Leslie Matrix Corazon et al (2016) using Leslie matrix to predict the number and growth rate in Riau Province in 2017. The result showed that the population of women in Riau Province tends to increase. In addition, research by Pratama et al (2013) find the dominant eigen value with several factors that affecting population growth, namely fertility, survival and vulnerable age of the population. The results showed that the dominant eigen value has the absolute value of the largest value and each dominant eigen value is more than one, less than one and equal to one. From the above description it is very necessary to determine the number of female population and know the rate of growth of female population in Eks-Karesidenan Kediri based on the birth rate and life expectancy using Leslie matrix. This paper will determine the number of female population in Karesidenan Kediri based on birthrate and life expectancy using Leslie matrix and also determine the growth rate of female population in Karesidenan Kediri by using Leslie matrix eigen value. 


\section{MATERIALS AND METHODS}

\section{Matrix}

According to Sukardjono (2000) a matrix is a set of numbers arranged in the form of a rectangle. Each number is called an entry or an element in the matrix. According to Kariadinata (2013), the matrix is a composition of a set of numbers in a rectangular array arranged by rows and columns, and placed between two parentheses. Meanwhile, according to Anton (2004), a matrix with $\mathrm{n}$ rows and $\mathrm{n}$ columns is called the square matrix of order $\mathrm{n}$, and the entries $a_{11}, a_{22}, \ldots, a_{n n}$ are said to be on the main diagonal of $\mathrm{A}$. If $\mathrm{A}$ is a matrix having $\mathrm{n}$ rows and $\mathrm{n}$ column (type $\mathrm{n} \times \mathrm{n}$ ), then $A$ can be written as:

$$
\left[\begin{array}{cccc}
a_{11} & a_{12} & \cdots & a_{1 n} \\
a_{21} & a_{22} & \cdots & a_{2 n} \\
\vdots & \vdots & & \vdots \\
a_{n 1} & a_{n 2} & \cdots & a_{n n}
\end{array}\right]
$$

\section{Inverse Matrix}

According to Gere \& Weaver (1987), the inverse of a quadratic matrix $A$, is written $A^{-1}$, and is defined as a matrix which, when multiplied by the matrix from $A$, will produce an identity matrix. The inverse matrix is always a square matrix with the same horizontal as the original matrix, and only the square matrix has the inverse. So the relationship between the matrix with the inverse is expressed as: $A A^{-1}=A^{-1} A=I$.

According to Adiwijaya (2014), let $A$ and $B$ be square matrices of equal size and $I$ is the identity matrix. If $A . B=I$ then $B$ is called the inverse of the matrix $A$ (on the other hand, $\mathrm{A}$ is the inverse of the matrix $B$ ). The notation that $B$ is an inverse matrix of $\mathrm{A}$ is $B=A^{-1}$ and vice versa $\mathrm{A}=$ $B^{-1}$

\section{Linear Combination}

The definition of Anton (2004) mentions a vector $\mathbf{w}$ called a linear combination of vectors $\mathbf{v}_{\mathbf{1}}, \mathbf{v}_{\mathbf{2}}, \ldots, \mathbf{v}_{\mathbf{r}}$ if the vector can be expressed in the form $\mathbf{w}=k_{l} \mathbf{v}_{\mathbf{1}}+k_{2} \mathbf{v}_{\mathbf{2}}$ $+\ldots+k_{r} \mathbf{v}_{\mathbf{r}}$, with $k_{1}, k_{2}, \ldots, k_{r}$ is a scalar

\section{Eigenvalues and Eigenvectors}

According to Kariadinata (2013), if $A$ is an $n \times n$ size matrix, then the nonzero vector $\mathrm{x}$ in $R^{n}$ is called an eigenvector of $A$ if $A \mathbf{x}$ is a scalar multiple of $\mathbf{x}$; Ie, $A x=$ $\lambda \mathbf{x}$ for any scalar $\lambda$. The scalar $\lambda$ is called the eigenvalue of $A$ and $\mathbf{x}$ is said to be the eigenvector corresponding to $\lambda$. To find the $n x n$ axial eigen matrix $A$ then $A \mathbf{x}=\lambda \mathbf{x}$ can be rewritten as $A \mathbf{x}=\lambda I \mathbf{x}$ or equivalent to $(\lambda I-A) \mathbf{x}=0$. To be an eigenvalue, there must be a nonzero solution of the equation $(\lambda I-A) \mathbf{x}=0$, obtained If and only if $\operatorname{det}(\lambda I-$ A) $=0$.

\section{Research Design}

The approach used in this research was quantitative approach. According to Sugiyono (2011), quantitative research methods can be interpreted as research methods based on positivism philosophy, used to examine the population or specific samples, data collection using research instruments, quantitative/statistical data analysis, with the aim of testing the hypothesis that has been established. Saifuddin (2004) suggested the results of quantitative research presented in the form of descriptions using the numbers. This type of research was descriptive research. While the research design used in this study is experimental research. The treatment that will be given to the data is application of Leslie Matrix theory based on application system using MAPLE.

\section{Research Stages}

The research method used in this research was: The first step was to determine the subject of research, while the subject of research were the growth of the female population at the birth rate and life expectancy in Karesidenan Kediri. The second step were (1) Collect research data, while the data collection research obtained from data Secondary in the Central Bureau of Statistics of East Java Province. (2) Data analysis and last draw conclusions. The existence of correct and sufficient data in a study will greatly determine the validity of the results of research being conducted. Data in research there is only one type that is secondary data. Secondary data were collected from several sources, including from the Central Bureau of Statistics (BPS) in 2010 - 2015 in East Java Province.

\section{Data Analysis Technique}

- Looking for the $a_{i}$ value (the fertility rate of the female population) derived from the divide between the average number of births born to a mother born in 2010-2015 divided by the number of female population in 2010 and the bi (life expectancy of the female population) Of the results of the division of the female population in 2015 with the number of female population in 2010.

- Produce Leslie matrix model on population growth.

- After the Leslie Matrix was formed then entered data on the number of female populations in 2015 to produce predictions of the female population in 2021.

- Look for positive eigen values in the matrix

- Using the equation approach for the dividing age distribution.

- Given the rate of female population for the period to come.

\section{RESULTS AND DISCUSSION}

This research was conducted by taking secondary data in some Central Statistics Agency in East Java Province with total population of 5 regencies and 2 cities in Karesidenan Kediri. The sample in this study was the number of female population from 2010 to 2015 , by comparison of the number of child births from 2010 to 2015. From the data then applied by applying Leslie matrix model to find population, eigen value. 


\section{Leslie Matrix Model in Population Growth}

In Leslie's model, women are divided into the same age groups. Specifically, suppose that the maximum age reached by any woman or female in the population is $\mathrm{M}$ years (or expressed in other units of time) and then the population is divided over the age group. So the time period in each group $\mathrm{M} / \mathrm{n}$ years. The age group will be explained by the following table:

Table 1. Age group matrix Model Leslie.

\begin{tabular}{cl}
\hline Age Group & Age Interval \\
\hline 1 & {$[0, M / n)$} \\
2 & {$[M / n, 2 M / n]$} \\
3 & {$[2 M / n, 3 M / n]$} \\
$\vdots$ & $\vdots$ \\
$(n-1)$ & {$[(n-1) M / n,(n-1) M / n]$} \\
$n$ & {$[(n-1) M / n, M]$} \\
\hline
\end{tabular}

For example known to the number of women or females in each group of $n$ groups at time $t=0$. In particular, for example $x_{1}^{(0)}$, there are women or females in the first group, $x_{2}^{(0)}$ women or females In the second, $x_{3}^{(0)}$ female or female group in the third group, and so on. With n number will be formed a column vector $\mathbf{x}^{(0)}$ that is:

$$
\mathbf{x}^{(0)}=\left[\begin{array}{c}
x_{1}^{(0)} \\
x_{2}^{(0)} \\
\vdots \\
x_{n}^{(0)}
\end{array}\right]
$$

This vector is called the initial age distribution vector.

Parameters In Leslie Matrix Model The process of birth and death processes between two consecutive observation times can be explained using the following demographic parameters:

Table 2. Parameters in the Leslie Matrix model.

\begin{tabular}{ll}
\hline$a_{i}$ & The average number of girls born to a \\
$i=1,2, \ldots, n$ & woman during her time in the age group to \\
& $-i$. \\
$b_{i}$ & The number of women in the age group to \\
$i=1,2, \ldots, n-1$ & $\begin{array}{l}-i, \text { who can be expected is still alive and } \\
\text { up to the age group. }\end{array}$ \\
\hline
\end{tabular}

By definition, it will be obtained that (i) $a_{i} \geq 0$ for $i=1,2, \ldots, n$ and (ii) $0<b_{i} \leq 1$ for $i=1,2, \ldots, n-1$. Next we will define the age distribution vector $\mathbf{x}^{(k)}$ at time $t_{k}$ with

$$
\mathbf{x}^{(k)}=\left[\begin{array}{c}
x_{1}^{(k)} \\
x_{2}^{(k)} \\
\vdots \\
x_{n}^{(k)}
\end{array}\right]
$$

,where, $x_{i}^{(k)}$ is the number of women or females in age group to- $i$ at the time $t_{k}$. At times $t_{k}$, At times $t_{k-1}$ and time $t_{k}$. Or mathematically

$$
x_{1}^{(k)}=a_{1} x_{1}^{(k-1)}+a_{2} x_{2}^{(k-1)}+\cdots+a_{n} x_{n}^{(k-1)}
$$

Number of women in the age group to - $(i+1)(i=$ $1,2, \ldots, n-1)$ at time $t_{k}$ Are women in groups to $-i$ at the time $t_{k-1}$ Who are still alive at the time $t_{k}$. Or mathematically,

$$
x_{i+1}^{(k)}=b_{i} x_{i}^{(k-1)}, i=1,2, \ldots, n-1
$$

By using matrix notation, equations (1) dan (2) by using matrix notation, equations

$$
\left[\begin{array}{c}
x_{1}^{(k)} \\
x_{2}^{(k)} \\
x_{3}^{(k)} \\
\vdots \\
x_{n}^{(k)}
\end{array}\right]=\left[\begin{array}{cccccc}
a_{1} & a_{2} & a_{3} & \cdots & a_{n-1} & a_{n} \\
b_{1} & 0 & 0 & \cdots & 0 & 0 \\
0 & b_{2} & 0 & \cdots & 0 & 0 \\
\vdots & \vdots & \vdots & & \vdots & \vdots \\
0 & 0 & 0 & \cdots & b_{n-1} & 0
\end{array}\right]\left[\begin{array}{c}
x_{1}^{(k-1)} \\
x_{2}^{(k-1)} \\
x_{3}^{(k-1)} \\
\vdots \\
x_{n}^{(k-1)}
\end{array}\right]
$$

Or more briefly

$$
\mathbf{x}^{(k)}=L \mathbf{x}^{(k-1)}, \text { with } k=1,2, \ldots
$$

Where $L$ is Leslie matrix

$$
L=\left[\begin{array}{cccccc}
a_{1} & a_{2} & a_{3} & \cdots & a_{n-1} & a_{n} \\
b_{1} & 0 & 0 & \cdots & 0 & 0 \\
0 & b_{2} & 0 & \cdots & 0 & 0 \\
\vdots & \vdots & \vdots & & \vdots & \vdots \\
0 & 0 & 0 & \cdots & b_{n-1} & 0
\end{array}\right]
$$

From equation (3) Found that

$$
\begin{aligned}
& \mathbf{x}^{(1)}=L \mathbf{x}^{(0)} \\
& \mathbf{x}^{(2)}=L \mathbf{x}^{(1)}=L^{2} \mathbf{x}^{(0)} \\
& \mathbf{x}^{(3)}=L \mathbf{x}^{(2)}=L^{3} \mathbf{x}^{(0)} \\
& \vdots \\
& \mathbf{x}^{(3)}=L \mathbf{x}^{(\mathrm{k}-1)}=L^{\mathrm{k}} \mathbf{x}^{(0)}
\end{aligned}
$$

Thus, if we know the start age distribution $\mathbf{x}^{(0)}$ and the Leslie matrix L, then we can determine the age distribution of women or females at any later time.

\section{Limiting Age Distribution (Limiting Age Distribution)}

Although the equation gives the age distribution of the population at any given time, it does not immediately give an overview of the dynamics of the growth process. It is necessary to investigate the eigenvalues and eigenvectors of Leslie's matrix. The eigenvalues of $\mathrm{L}$ are the roots of the characteristic polynomial. The characteristic polynomial of Leslie's matrix is 


$$
\begin{gathered}
p(\lambda)=\lambda^{n}-a_{1} \lambda^{n-1}-a_{2} b_{1} \lambda^{n-2}-a_{3} b_{1} b_{2} \lambda^{n-3} \ldots \\
-a_{n} b_{1} b_{2} \ldots b_{n-1}
\end{gathered}
$$

Will be given the theorems related to Leslie's matrix, as follows:

\section{Theorem 1}

A Leslie matrix $L$ has a unique positive eigen value $\lambda_{1} \ldots$ This eigenvalue has a multiplicity 1 and has an eigenvector $\mathbf{x}_{\mathbf{1}}$ whose all entries are positive.

\section{Theorem 2}

if $\lambda_{1}$ Is the unique positive eigen value of a Leslie matrix $L$ and if $\lambda_{i}$ is any real or complex eigenvalues of $L$, so $\left|\lambda_{k}\right| \leq \lambda_{1}$.

\section{Theorem 3}

If two entries are successive $a_{i}$ and $a_{i+1}$ in the first row of a Leslie matrix of $L$ is not equal to zero then the positive eigenvalue of $\mathrm{L}$ is dominant.

In the next section it will always be assumed that the terms of theorem 3 are met. It will be assumed that $L$

Can diagonalize. It is not necessary for the conclusions to be taken, but this will simplify the argument. In this case, $L$ have $n$ eigenvalue, $\lambda_{1}, \lambda_{2}, \ldots, \lambda_{n}$, Which need not be different from each other, and $n$ Linearly independent eigenvectors $\mathbf{x}_{1}, \mathbf{x}_{2}, \ldots, \mathbf{x}_{n}$, Which corresponds to the eigenvalues. In this list will be placed eigenvalues $\lambda_{1}$ the dominant first. The diagonalization of $L$ will be given by the equation

$$
L=P D P^{-1}, L=P\left[\begin{array}{ccccc}
\lambda_{1} & 0 & 0 & \cdots & 0 \\
0 & \lambda_{2} & 0 & \cdots & 0 \\
\vdots & \vdots & \vdots & & \vdots \\
0 & 0 & 0 & \cdots & \lambda_{n}
\end{array}\right] P^{-1}
$$

From this equation obtained

$$
L^{k}=P\left[\begin{array}{ccccc}
\lambda_{1}^{k} & 0 & 0 & \cdots & 0 \\
0 & \lambda_{2}^{k} & 0 & \cdots & 0 \\
\vdots & \vdots & \vdots & & \vdots \\
0 & 0 & 0 & \cdots & \lambda_{n}^{k}
\end{array}\right] P^{-1} \text { for } k=1,2, \cdots
$$

For any vector age distribution first $\mathbf{x}^{(\mathbf{0})}$ it will be obtained.

$$
L^{k} \mathbf{X}^{(0)}=P\left[\begin{array}{ccccc}
\lambda_{1}^{k} & 0 & 0 & \cdots & 0 \\
0 & \lambda_{2}^{k} & 0 & \cdots & 0 \\
\vdots & \vdots & \vdots & & \vdots \\
0 & 0 & 0 & \cdots & \lambda_{n}^{k}
\end{array}\right] P^{-1} \mathbf{x}^{(0)} \text { for } k=1,2, \ldots
$$

By dividing the two sections of this equation by $\lambda_{1}^{k}$ And by using that fact $\mathbf{x}^{(k)}=L^{k} \mathbf{x}^{(0)}$, It will be obtained $\frac{1}{\lambda_{1}^{k}} \mathbf{x}^{(k)}=P\left[\begin{array}{ccccc}1 & 0 & 0 & \cdots & 0 \\ & \left(\frac{\lambda_{2}}{\lambda_{1}}\right)^{k} & 0 & \cdots & 0 \\ 0 & \vdots & \vdots & & \vdots \\ 0 & 0 & 0 & \cdots & \left(\frac{\lambda_{n}}{\lambda_{1}}\right)^{k}\end{array}\right] P^{-1} \mathbf{x}^{(0)}$

because $\lambda_{1}$ Is the dominant eigenvalue that is $\left|\lambda_{1}\right|>\left|\lambda_{i}\right|$, then $\left|\lambda_{i} / \lambda_{1}\right|<1$ for $i=2,3, \ldots, n$. It is clear that $\left(\lambda_{i} / \lambda_{1}\right)^{k} \rightarrow 0$ if $k \rightarrow \infty$ for $i=2,3, \ldots, n$.

By using this statement, Can take a limit from both sides of (6) to get

$\lim _{k \rightarrow \infty}\left\{\frac{1}{\lambda_{1}^{k}} \mathbf{x}^{(k)}\right\}=P\left[\begin{array}{ccccc}1 & 0 & 0 & \cdots & 0 \\ 0 & 0 & 0 & \cdots & 0 \\ \vdots & \vdots & \vdots & & \vdots \\ 0 & 0 & 0 & \cdots & 0\end{array}\right] P^{-1} \mathbf{x}^{(0)}$

It will then be declared the first entry of the column vector $P^{-1} \mathbf{X}^{(0)}$.

With constants $c$, then $P^{-1} \mathbf{x}^{(0)}=\left[\begin{array}{c}c \\ c_{1} \\ \vdots \\ c_{n-1}\end{array}\right]$.

This result is entered into the equation (7) that is

$$
\begin{gathered}
\lim _{k \rightarrow \infty}\left\{\frac{1}{\lambda_{1}^{k}} \mathbf{x}^{(k)}\right\}=P\left[\begin{array}{ccccc}
1 & 0 & 0 & \cdots & 0 \\
0 & 0 & 0 & \cdots & 0 \\
\vdots & \vdots & \vdots & & \vdots \\
0 & 0 & 0 & \cdots & 0
\end{array}\right]\left[\begin{array}{c}
c \\
c_{1} \\
\vdots \\
c_{n-1}
\end{array}\right] \\
=\left[\mathbf{x}_{1}\left|\mathbf{x}_{2}\right| \mathbf{x}_{3}|\cdots| \mathbf{x}_{n}\right]\left[\begin{array}{ccccc}
1 & 0 & 0 & \cdots & 0 \\
0 & 0 & 0 & \cdots & 0 \\
\vdots & \vdots & \vdots & & \vdots \\
0 & 0 & 0 & \cdots & 0
\end{array}\right]\left[\begin{array}{c}
c \\
c_{1} \\
\vdots \\
c_{n-1}
\end{array}\right] \\
=\left[\mathbf{x}_{1}\left|\mathbf{x}_{2}\right| \mathbf{x}_{3}|\cdots| \mathbf{x}_{n}\right]\left[\begin{array}{c}
c \\
0 \\
\vdots \\
0
\end{array}\right]=c \mathbf{x}_{1}
\end{gathered}
$$

So the right side of (7) Can be written as $c \mathbf{x}_{1}$, where $c$ Is a positive constant that depends only on the vector of age distribution first $\mathbf{x}^{(0)}$. so (7) be

$$
\lim _{k \rightarrow \infty}\left\{\frac{1}{\lambda_{1}^{k}} \mathbf{x}^{(k)}\right\}=c \mathbf{x}_{1}
$$

Equation (8) Provide approximation

$$
\mathbf{x}^{(k)} \cong c \lambda_{1}^{k} \mathbf{x}_{1}
$$

For large k values. From (9) also get

$$
\mathbf{x}^{(k-1)} \cong c \lambda_{1}^{k-1} \mathbf{x}_{1}
$$

By comparing equations (9) and the equation (10) obtained 


$$
\mathbf{x}^{(k)} \cong \lambda_{1} \mathbf{x}^{(k-1)}
$$

For large $\mathrm{k}$ values. This means that for large time values each age distribution vector is a scalar multiple of the previous age distribution vector, and the scalar is the positive eigenvalue of Leslie's matrix. Consequently, the proportion of females in each group of age groups will be constant. Then will be reviewed again equation (12) Which gives the age distribution vector of the population for a long time

$$
: \mathbf{x}^{(k)} \cong c \lambda_{1}^{k} \mathbf{x}_{1}
$$

Three cases will appear in accordance with the eigenvalues $\lambda_{1}$ : (i) The amount of population will ultimately tend to increase / increase if $\lambda_{1}>1$, (ii) The total population will ultimately tend to decrease / decrease if $\lambda_{1}<1$, (iii) Population will tend to be stable / fixed if $\lambda_{1}=1$. If the population tends to decrease then it can be said also that the population growth rate is negative, whereas if the population number increases it can be said also that the population growth rate is positive.

\section{Data on Population of Women in Eks Karesidenan Kediri}

The following is data on the number of female population from 2010-2015 in Eks Karesidenan Kediri. Since only a few women over the age of 45 years who gave birth to a child, it will be restricted from a population of women between the ages of 10 and 44 years this is due to the age of female fertility interval of 10-44 years. This data is for the age group with the period of 5 years, so the total number is 14 age groups.

Table 3. Number of Female Population, Number of Children Born Year, fertility rate and life expectancy of female population in 2010-2015.

\begin{tabular}{clllll}
\hline Age Group & $\mathbf{2 0 1 0}$ & Birth & $\mathbf{2 0 1 5}$ & ai & bi \\
\hline $0-4$ & 231.185 & 0 & 219.965 & 0 & 0,9547 \\
$5-9$ & 225.476 & 0 & 220.705 & 0 & 0,9752 \\
$10-14$ & 227.434 & 2.056 & 219.895 & 0,0090 & 0,9215 \\
$15-19$ & 209.842 & 42.448 & 209.579 & 0,2023 & 0,9372 \\
$20-24$ & 196.924 & 49.657 & 196.662 & 0,2522 & 1,0339 \\
$25-29$ & 217.015 & 50.306 & 203.599 & 0,2318 & 0,9730 \\
$30-34$ & 219.892 & 43.089 & 211.145 & 0,1960 & 1,0118 \\
$35-39$ & 225.483 & 40.653 & 222.497 & 0,1803 & 1,0209 \\
$40-44$ & 229.065 & 40.272 & 230.192 & 0,1758 & 0,9869 \\
$45-49$ & 210.144 & 0 & 226.054 & 0 & 0,9566 \\
$50-54$ & 171.049 & 0 & 201.023 & 0 & 1,0104 \\
$55-59$ & 137.422 & 0 & 172.825 & 0 & 0,9078 \\
$60-64$ & 104.624 & 0 & 124.756 & 0 & 2,7506 \\
$65+$ & 269.021 & 0 & 287.779 & 0 & - \\
Total & 2.874 .576 & 268.480 & 2.946 .676 & - & - \\
\hline
\end{tabular}

Table 4. Number of Female Population,in 2010 and 2015 and prediction number of female population in 2021.

\begin{tabular}{clll}
\hline Age Group & $\mathbf{2 0 1 0}$ & $\mathbf{2 0 1 5}$ & $\mathbf{2 0 2 1}$ \\
\hline $0-4$ & 231.185 & 219.965 & 263.137 \\
$5-9$ & 225.476 & 220.705 & 210.000 \\
$10-14$ & 227.434 & 219.895 & 215.231 \\
$15-19$ & 209.842 & 209.579 & 202.633 \\
$20-24$ & 196.924 & 196.662 & 196.417 \\
$25-29$ & 217.015 & 203.599 & 203.328 \\
$30-34$ & 219.892 & 211.145 & 198.101 \\
$35-39$ & 225.483 & 222.497 & 213.636 \\
$40-44$ & 229.065 & 230.192 & 227.147 \\
$45-49$ & 210.144 & 226.054 & 227.176 \\
$50-54$ & 171.049 & 201.023 & 216.243 \\
$55-59$ & 137.422 & 172.825 & 203.113 \\
$60-64$ & 104.624 & 124.756 & 156.890 \\
$65+$ & 269.021 & 287.779 & 343.153 \\
Total & 2.874 .576 & 2.946 .676 & 3.076 .205 \\
\hline
\end{tabular}

From the data above will be done data analysis by looking for parameter $a_{i}$ (fertility number) and $b_{i}$ parameter (life expectancy). Leslie's matrix model can be used to determine the number of female population the next 6 years. Using Leslie's matrix, based on table 3 the female population is divided into several age-class intervals, with the female fertility age interval of 15-44 years. Here is a settlement step to predict the number and growth rate of Eks Karesidenan Kediri in 2021.

Further analysis will be done using the Maple program to determine the dynamics of the growth process based on eigenvalues and eigenvectors of Leslie matrix. Then by using the equation approach for the dividing age distribution $\mathbf{x}^{(k)} \cong \lambda_{1} \mathbf{x}^{(k-1)}$ will be sought the dynamics of growth of female population in Eks Karesidenan Kediri.

Having formed Leslie's matrix, based on the equation (3) to predict the number of women in 2021 is $\mathbf{x}^{(k)}=$ $L \mathbf{x}^{(k-1)}$ 


$\left[\begin{array}{cccccccccccccccc}0 & 0 & 0.0090 & 0.2023 & 0.2522 & 0.2318 & 0.1960 & 0.1803 & 0.1758 & 0 & 0 & 0 & 0 & 0 \\ 0.9547 & 0 & 0 & 0 & 0 & 0 & 0 & 0 & 0 & 0 & 0 & 0 & 0 & 0 \\ 0 & 0.9752 & 0 & 0 & 0 & 0 & 0 & 0 & 0 & 0 & 0 & 0 & 0 & 0 \\ 0 & 0 & 0.9215 & 0 & 0 & 0 & 0 & 0 & 0 & 0 & 0 & 0 & 0 & 0 \\ 0 & 0 & 0 & 0.9372 & 0 & 0 & 0 & 0 & 0 & 0 & 0 & 0 & 0 & 0 \\ 0 & 0 & 0 & 0 & 1.0339 & 0 & 0 & 0 & 0 & 0 & 0 & 0 & 0 & 0 \\ 0 & 0 & 0 & 0 & 0 & 0.9730 & 0 & 0 & 0 & 0 & 0 & 0 & 0 & 0 \\ 0 & 0 & 0 & 0 & 0 & 0 & 1.0118 & 0 & 0 & 0 & 0 & 0 & 0 & 0 \\ 0 & 0 & 0 & 0 & 0 & 0 & 0 & 1.0209 & 0 & 0 & 0 & 0 & 0 & 0 \\ 0 & 0 & 0 & 0 & 0 & 0 & 0 & 0 & 0.9869 & 0 & 0 & 0 & 0 & 0 \\ 0 & 0 & 0 & 0 & 0 & 0 & 0 & 0 & 0 & 0.9566 & 0 & 0 & 0 & 0 \\ 0 & 0 & 0 & 0 & 0 & 0 & 0 & 0 & 0 & 0 & 1.0104 & 0 & 0 & 0 \\ 0 & 0 & 0 & 0 & 0 & 0 & 0 & 0 & 0 & 0 & 0 & 0.9078 & 0 & 0 \\ 0 & 0 & 0 & 0 & 0 & 0 & 0 & 0 & 0 & 0 & 0 & 0 & 2.7506 & 0\end{array}\right]\left[\begin{array}{l}219.965 \\ 220.705 \\ 219.895 \\ 209.579 \\ 196.662 \\ 203.599 \\ 211.145 \\ 222.497 \\ 230.192 \\ 226.054 \\ 201.023 \\ 172.825 \\ 124.756 \\ 287.779\end{array}\right]=\left[\begin{array}{l}263.137 \\ 210.000 \\ 215.231 \\ 202.633 \\ 196.417 \\ 203.328 \\ 198.101 \\ 213.636 \\ 227.147 \\ 227.176 \\ 216.243 \\ 203.113 \\ 156.890 \\ 343.153\end{array}\right]$

\section{CONCLUSIONS}

Using the Maple programe a positive eigenvalue and its eigenvector can be approximated by $\lambda_{1}=1,010249$. Then by using the equation approach for the dividing age distribution: $\quad \mathbf{x}^{(k)} \cong \lambda_{1} \mathbf{x}^{(k-1)}$. $\quad$ So $\quad \mathbf{x}^{(k)} \cong$ $1,010249 \mathbf{x}^{(k-1)}$. From the eigenvalues obtained $\lambda_{1}>1$ So that every five years the population of women in Eks Karesidenan Kediri will tend to increase or in other words the growth rate of female population in Eks Karesidenan Kediri tends to be positive.

\section{REFERENCES}

Adiwijaya. 2014. Matrix and Vector Space Applications. Graha Ilmu. Yogyakarta

Anton, H. \& Rorres, C. 1988. Application of Linear Algebra. Erland. Jakarta. Jakarta.

2004. Linear Elementary Algebra (app version). Erland.

Central Bureau of Statistics. 2013. Indonesian Population Projection 2010-2035, Jakarta.

Corazon, C.M., et al. 2016. Leslie Matrix Applications to Predict the Number and Growth Rate of Women in Riau Province in the Year 2017. Journal of Mathematics and Statistics (JSMS), 2 (3), $1-11$

Iswanto, Ripno July. 2012. Applied and Applied Mathematics Modeling. Graha Ilmu. Yogyakarta.

Kariadinata, Rahayu. 2013. Algebra Matrix Elementer. CV Pustaka Setia. Bandung.

Kartono.2005. Maple for Differential Equations.Graha Ilmu. Yogyakarta.

Pratama, Yudi, et al. 2013. Leslie Matrix Application to Predict the Number and Rate of Growth of a Population. Bimaster: Math Scientific Bulletin. Stat. And Applied, 2 (3), 163-172.

Tarumingkeng, R.C, 1994. Population Dynamics (Quantitative Ecology Assessment), Pustaka Sinar Harapan. Jakarta.

Yeargers, Edward K. 1996. An introdution to the mathematics of Biology: with computer algebra models, Birkhauser, Boston 